\title{
1
}

\section{Introductory Insights to Climate Change Challenges}

\author{
Felix N. Hammond, Colin A. Booth, Jessica E. Lamond \\ and David G. Proverbs
}

\subsection{Introduction}

The epic phenomenon of the 21st century, with which this book is concernedclimate change - was originally designated, or rather started, as a concern for global warming. A distinction is now maintained between the two terminologies. Global warming is restricted to the measurable rapid warming of the Earth's surface identified from a study of worldwide temperature records since 1880 attributable to human activities (Pielke et al., 2004; Pielke, 2005; Nodvin, 2010; Riebeek, 2010). Climate change conversely now signifies 'changes in the state of the climate that can be identified by changes in the average and/or the variability of its properties ... that persists [sic] for an extended period, typically decades or longer' (Nodvin, 2010). Climatic events associated with global warming include volatility and extremities of climatic events such as rainfall, sea level rise, drought, volcanic activities, hurricanes, loss of biodiversity, heightened storm intensity, frequent heat waves, altered precipitation patterns, reversal of ocean current and flooding, amongst others (Goulder, 2006; Tamirisa, 2007; American Institute of Physics [AIP], 2010). Because the climate of the earth is driven by the surface temperature of the earth (Lindsey, 2009), global warming is the prime cause of variation in global climate. To this end, the two phenomena cannot actually be decoupled in any serious sense; anything that influences global warming ultimately influences climate change.

There are areas of substantial uncertainty about climate change. What scientists agree on is that climate change is real and that if not curbed could result in catastrophic consequences (Stern et al., 2006). As a result, the past two decades have seen unprecedented concern about the consequences of climate change and the cost of reducing its long-term impact. Climate

Solutions to Climate Change Challenges in the Built Environment, First Edition. Edited by Colin A. Booth, Felix N. Hammond, Jessica E. Lamond and David G. Proverbs. (C) 2012 Blackwell Publishing Ltd. Published 2012 by Blackwell Publishing Ltd. 
change is now very high on the worldwide political agenda. This has led to major international initiatives such as the United Nations Framework Convention on Climate Change (UNFCCC), the Kyoto Protocol, the establishment of the United Nations Intergovernmental Panel on Climate Change and the 1992 Rio de Janeiro Conference. These are aimed at achieving a globally coordinated accord on adapting and mitigating climate change. 'Changing land cover and land use' have been implicated as a 'major underlying cause of' global warming (Intergovernmental Panel on Climate Change, Task Group on Data and Scenario Support for Impact and Climate Assessment [IPCC-TGICA], 2007). Changing land cover and land use are built environment and agricultural activities such as the construction of buildings, roads and highways and other infrastructure. The objective of this volume is to improve understanding of how built environment activities potentially induce global warming and climate change but, moreover, to highlight solutions to these challenges.

As the ensuing chapters show, climate change is a very intricate phenomenon, the understanding and handling of which involve mathematics, biology, physics, politics, economics, industrial science, climatology and so forth almost in equal measure (Lawson, 2006; AIP, 2010). That said, the complex thrust of the ongoing climate change debate and research can be distilled into five answerable focal questions: (1) Is the Earth temperature increasing with the possibility of reaching an intolerable limit at some point? (2) What is the threat that this poses to the very survival of life on Earth? (3) What are the fundamental cause(s)? (4) For our present purpose, are activities of the built environment elemental contributors to the warming of the Earth? And (5) what can be done, if anything, to forestall or cope with the problem of rising Earth temperature?

This volume contains 25 chapters that have attempted to address aspects of these questions from diverse perspectives, primarily by looking at the questions from the interdependent relations between climate change and built environment endeavours. For the sake of the uninitiated reader, it is useful to provide a brief overview of climate change theory before exploring its connections with the built environment.

\subsection{Climate Change Theory}

To understand climate change we must begin with an understanding of the term climate. In the text, climate has been used in two main senses, the narrow and broader sense. According to the IPCC,

Climate in a narrow sense is usually defined as the "average weather," or more rigorously, as the statistical description in terms of the mean and variability of relevant quantities over a period of time ranging from months to thousands or millions of years. The classical period is 30 years, as defined by the World Meteorological Organization (WMO). These quantities are most often surface variables such as temperature, precipitation, and wind. Climate in a wider sense is the state, including a statistical description, of the climate system. (IPCC, 2007b) 


\section{Whereas:}

In a broader sense, [however] climate is the status of the climate system which comprises the atmosphere, the hydrosphere, the cryosphere, the surface lithosphere and the biosphere. These elements determine the state and dynamics of the Earth's climate. ([WMO], 2010)

In this book we are concerned with climate in the narrow sense.

\subsubsection{Primary Cause of Climate Change}

The problems of global warming and climate change have arisen because of the Earth's climate dependence on solar radiation (energy from the sun) as its primary source of power (Trenberth et al., 2009; Congressional Budget Office [CBO], 2005). The solar radiation from the Sun is generated by its surface heat which is about $5500^{\circ} \mathrm{C}$ (Lindsey, 2009). The Sun transmits this heat or solar energy towards the Earth to power the Earth's climate. For at least two reasons, only a fraction of the solar radiation from the Sun ultimately reaches the Earth surface. The intensity of thermal energy reduces with distance. Thus, being some 150 million kilometres (93 million miles) away from the Sun, the intensity of the solar energy reduces drastically by the time it travels this distance to make contact with the surface of the Earth (AIP, 2010). Further reduction in the intensity of the solar energy from the Sun occurs as it penetrates the atmosphere, which encircles the Earth in order to reach the Earth's surface. By the time the solar energy reaches the top surface of the atmosphere, its intensity has diminished substantially. The atmosphere consists of nongreenhouse gases such as nitrogen and oxygen; water vapour; and greenhouse gases carbon dioxide, methane and others. On contact with the top surface of the atmosphere, about $30 \%$ of ultraviolet light is re-radiated by the atmosphere back to space. Of the remaining $70 \%$ that manages to penetrate the surface of the atmosphere, $19 \%$ is trapped (absorbed) by the greenhouse gases in the atmosphere. Approximately 51\% of the ultraviolet light then passes through the atmosphere onto the Earth system - land surface or ocean (AIP, 2010). Whilst this is an on-going process, the Earth's temperature does not increase endlessly because energy is also dissipated away from the Earth.

The ultraviolet light from the Sun that manages to penetrate the atmosphere warms up objects on the Earth's surface. The warmed Earth emits heat energy in the form of infrared radiation back into space that cools down the Earth. The intensity of the infrared radiation emitted by the Earth is equal to that of the ultraviolet radiation it receives from the Sun. Without the intervention of the atmosphere, the process of radiations from the Sun to the Earth, and from the Earth to the Sun, would leave the temperature of the Earth unaltered or constant at $-18^{\circ} \mathrm{C}$ (similar to that of the moon which is approximately the same distance from the Sun as the Earth). However, not all of the infrared radiation from the Earth reaches space. Indeed, NASA estimates that only about $6 \%$ of the infrared radiation 
from the Earth does so. This is because whilst the greenhouse gases in the atmosphere permit a considerable volume of the ultraviolet radiation from the Sun to penetrate the atmosphere to reach the Earth, they are not that transparent to the infrared radiation from the Earth. The greenhouse gases absorb the infrared radiation from the Earth and re-radiate a significant proportion back to the Earth's surface. This is then reflected back to the atmosphere and then back again onto the Earth surface and so forth. This process is called the greenhouse effect and it ultimately increases the surface temperature of the Earth. As a result, the average temperature of the earth surface hovers around $15^{\circ} \mathrm{C}$, some $33^{\circ} \mathrm{C}$ warmer than a body without an atmosphere. Carbon dioxide $\left(\mathrm{CO}_{2}\right)$ is the main greenhouse gas implicated for the greenhouse effect which is causing global warming and hence climate change (Oregon Wild, 2007). Although $\mathrm{CO}_{2}$ is not the most impenetrable of the gases, it is seen as most important because its levels have increased the most and hence it has influenced global warming the most. As Svante Arrhenius (the Swedish chemist who made the earliest effort to estimate the actual effect of greenhouse gases on climate in 1895) found, removing all $\mathrm{CO}_{2}$ from the atmosphere would lower global temperature by $31^{\circ} \mathrm{C}$ (Warwick and Wilcoxen, 2002).

Though available data show that the greenhouse effect has caused the Earth temperature to fluctuate over time, its net effect in the twentieth century is a warming of the earth surface above that of the pre-industrial era. It is estimated that over the last century, the global Earth surface temperature has increased by about between $0.6^{\circ} \mathrm{C}$ and $0.8^{\circ} \mathrm{C}$ and is set to increase further in the next century. Though the forecasts may not all be identical owing to the variety of bodies involved in this research, there may safely be considered a overwhelming majority of experts predicting the warming of the earth resulting from greenhouse effects.

Since $\mathrm{CO}_{2}$ is seen as the main culprit of climate change, it is useful to appreciate the source of atmospheric $\mathrm{CO}_{2}$ and how its concentration can be regulated to generate a favourable Earth surface temperature. $\mathrm{CO}_{2}$ is emitted through natural processes as well as through human actions. The planet Earth has a fixed volume of carbon (Oregon Wild, 2007). This can, however, be circulated and stored (that is, can be taken out of the atmosphere). Carbon is generally stored in all living things: rocks, sediments and the air (Holmes, 2008; Sedjo, 1993). Through a combination of natural activities (such as volcanic activities, death and decomposition of organic matter and living plants, leaves, animals and humans) and human actions (such as soil excavations and combustion of fossils through the use of fossil fuels - high carbon containing fuels - such as coal, natural gas, gasoline and oil for heating, transportation and electricity), $\mathrm{CO}_{2}$ is released and shifted into the atmosphere (Oregon Wild, 2007).

The built environment is crucial in the climate change and global warming dialogue. It is estimated that nearly half $(50 \%)$ of $\mathrm{UK} \mathrm{CO}_{2}$ emissions are buildings related, and $27 \%$ of $\mathrm{UK} \mathrm{CO}_{2}$ emissions come from housing (Department of Trade and Industry [DTI], 2006). As implied in the name, built environment refers to the aspects of the physical environment that have been built upon by humans. This mainly consists of the construction of 
buildings and infrastructure. This human-driven activity results in the release of considerable quantities of $\mathrm{CO}_{2}$ into the atmosphere in many ways. Firstly construction involves excavation of topsoils, a process that releases stored carbons in the soil into the atmosphere. Additionally, construction is heavily dependent on the use of machines that are powered by either electricity or fossil fuels such as gasoline, oil or coal. Besides the extraction, manufacturing and transporting construction materials contribute some $10 \%$ of UK $\mathrm{CO}_{2}$ emissions (DTI, 2006). Then again, the use and management of the constructed facilities involve substantial reliance of fossil fuels for heating, lighting and the operation of facilities such as computers, lifts and projectors. Built environment transportation systems such as trains, motor vehicles and air transport also make heavy use of fossil fuels. There is little doubt, therefore, that the built environment contributes to the quantity of $\mathrm{CO}_{2}$ in the atmosphere and hence to global warming and climate change.

\subsection{The Controversy and Context}

Climate change is not without its own raging controversies. That climate change is influenced by greenhouse effect, and that human activities have increased the concentration of the $\mathrm{CO}_{2}$ component in the greenhouse gases, are well accepted by experts in the field. There are, however, many controversial areas and uncertainties surrounding the science of climate change which are impeding progress in finding cost-effective solutions to the issue. The starting point of this debate is the anthropogenic climate change theory, or what is also sometimes referred to as man-made catastrophic climate change theory. The Intergovernmental Panel on Climate Change, comprising over 1000 scientists from over 100 countries, being the official mouthpiece of government across the globe on climate change and sponsored by the United Nations, remains the ardent proponent of this theory. Whilst $\mathrm{CO}_{2}$ emissions may emanate from natural causes or human actions, this theory holds that the contributions from human activities alone are responsible for a significant increase in global warming. The IPCC concludes that:

Global atmospheric concentrations of $\mathrm{CO}_{2}$ [carbon dioxide], methane and nitrous oxide have increased markedly as a result of human activities since 1750 and now far exceed pre-industrial values determined from ice cores spanning many thousands of years.... The atmospheric concentrations of $\mathrm{CO}_{2}$ and $\mathrm{CH}_{4}$ in 2005 exceed by far the natural range over the last 650000 years. Global increases in $\mathrm{CO}_{2}$ concentrations are due primarily to fossil fuel use, with land-use change providing another significant but smaller contribution. It is very likely that the observed increase in $\mathrm{CH}_{4}$ concentration is predominantly due to agriculture and fossil fuel use. The increase in $\mathrm{N}_{2} \mathrm{O}$ concentration is primarily due to agriculture... There is very high confidence that the global average net effect of human activities since 1750 has been one of warming, with a radiative forcing of +1.6 . $(2007 \mathrm{~b}, 37)$ 
In 2008, in affirmation of the above, the US Congressional Budget Office concluded that '[h] uman activities are producing increasingly large quantities of greenhouse gases, particularly carbon dioxide $\left(\mathrm{CO}_{2}\right)$, which accumulate in the atmosphere and create costly changes in regional climates throughout the World' (CBO, 2008). Based on the anthropogenic climate change theory, Sir Nicholas Stern et al. estimate that 'the overall cost and risks of climate change will be equivalent to losing at least $5 \%$ of global GDP each year, now and forever... these are risks of major disruption to economic and social activity, on a scale similar to those associated with the great wars and the economic depression of the first half of the 20th century' (2006). This brings the solution or at least moderation of the rate of global warming within the province of public policy; if it is caused by conscious human action, then it can be redressed through policy. After all, the aim of policy, whether economic or another, is to reform, shape or direct conscious human actions along lines that are compatible with the outcomes expected. Hence Stern et al. (2006), could assert that 'the benefit of strong early action outweigh the costs'. This probably explains why those in charge of policy - government policy advisers, government departments, United Nations, the World Bank and so on - have embraced the anthropogenic climate change theory and are working on policy solutions to climate change. At least by setting policy actions to regulate the volume and rate of human action contributions to climate change, policy makers and politicians are demonstrating to voters that they are performing their primary function - the reason why they exist - which is to promote the wellbeing of people. There is no presumption here that this is the motivation for the policy conclusion drawn. The main policy lines followed in controlling human actions for the benefit of climate change include: emission trading programs, emission taxes, performance standards and technology programs (Goulder, 2006).

There are great areas of uncertainty about the science of climate change. For instance, there is still uncertainty about the unique contribution of atmospheric water vapour, clouds and aerosols to climate change (Warwick and Wilcoxen, 2002). Besides these uncertainties, spells of global cooling have led to scepticism about whether the ongoing global warming can indeed reach the point of catastrophe.

Horner (2007) points out that the massive funding of climate change research was prompted by "consensus" panic over "global cooling", As Bray (1999) asserts, 'before we take global warming as a scientific truth, we should note that the opposite theory was once scientific verity'. Along the same lines, Balling (1992) avers:

Could the [cold] winters of the late 1970s be the signal that we were returning to yet another ice age? According to many outspoken climate scientists in the late 1970 s, the answer was absolutely yes and we needed action to cope with the coming changes.... However, some scientists were sceptical, and they pointed to a future of global warming, not cooling, resulting from a continued build up of greenhouse gases. These scientists were in the minority at the time. 
According to Crichton (2004):

"Just think how far we have come!" Henley said. "Back in the 1970s, all the climate scientists believed an ice age was coming. They thought the world was getting colder. But once the notion of global warming was raised, they immediately recognized the advantages. Global warming creates a crisis, a call to action. A crisis needs to be studied, it needs to be funded.

Michaels (2004) posits,

Thirty years ago there was much scientific discussion among those who believed that humans influenced the ... reflectivity [which would] cool the Earth, more than... increasing carbon dioxide, causing warming. Back then, the "coolers" had the upper hand because, indeed, the planet was cooling. ... But nature quickly shifted gears. ... Needless to say, the abrupt shift in the climate caused almost as abrupt a shift in the balance of scientists who predictably followed the temperature.

The evidence of global cooling after the pre-industrial era brings into question the conclusiveness of anthropogenic climate change theory. For, if human activities contribute significantly to atmospheric $\mathrm{CO}_{2}$ concentration, then since human activities have increased since the age of industrialisation, we should expect the Earth's temperature to head upwards only. But as the above quotes show, this has not been the case; there have been periods of severe cooling even to the point of causing concern about a possible global ice age. If the Earth has experienced so great a cooling in the past and it is now warming, it may well be that global cooling alternates with global warming and that the warming we experience today would eventually be replaced by a period of global cooling. This suggests at least that a better understanding of the underlying causes of the global temperature alternation is required in order to be able to make long-range predictions about global warming.

This lack of complete understanding has led to a conundrum. Subscribers to catastrophic anthropogenic climate change theory such as the IPCC have called for an immediate reduction of human activities that generate $\mathrm{CO}_{2}$. The cost of doing so is phenomenal though believed to be trivial compared to the cost of the global warming-induced catastrophe that awaits us. Huge scarce resources are also now being directed towards enforcing such $\mathrm{CO}_{2}$ reduction policies. Sceptics towards this theory hold the view that, since the contribution to temperature changes by human activities are actually very small and the current warming is likely to be replaced by cooling, there is no economic justification, or rather it will be a wasteful and unnecessary infraction on enjoyment to curtail certain human activities, spend all those resources and defer economic growth for a phenomena over which humans have no real control (Lawson, 2006). It is worth noting that this view is in the minority, and nearly all government and international development agencies hold tenaciously to the anthropogenic climate change theory. 
Controversy aside and regardless of the degree of accuracy which climate models of future warming can claim, it is clear that the planet has warmed in the recent past. This is engendering extreme weather events that are damaging to the built environment. Also there is little doubt that man-made emissions have made some contribution to the warming and that the continued unchecked generation of greenhouse gases makes catastrophic warming scenarios more likely to occur. Climate change mitigation policy is here to stay for the foreseeable future. It is very important to note that alongside the threat of climate change there are also opportunities. These could represent new economic possibilities or the chance to improve the built or natural environment. New opportunities may offset the risks and reduce the need for society to defend existing buildings and livelihood. Built environment professionals and stakeholders should therefore seek to pursue climate mitigation and adaptation practices. To this end, this book presents solutions to some of the issues connected with climate change.

\subsection{Organisation of the Book}

Based on the challenges outlined above, this book comprises five main themes: (1) climate change experiences (Chapters 1, 2, 3, 5 and 6), (2) urban landscape development (Chapters 4, 9, 10, 11, 12 and 14), (3) urban management issues (Chapters 13, 15, 16, 17, 18, 19 and 20), (4) measurement of impact (Chapters 7, 8, 21 and 22) and (5) the future (Chapters 23, 24 and 25).

\section{References}

American Institute of Physics (2010) A hyperlinked history of climate change science. Spencer Weart and American Institute of Physics, College Park, MD. Available from http://www.aip.org/history/climate/summary.htm.

Balling, R.C., Jr. (1992) The Heated Debate: Greenhouse Prediction versus Climate Reality. Pacific Research Institute for Public Policy, San Francisco.

Bray, A.J. (1999) The Ice Age cometh. Policy Review, 58, 82-84.

Congressional Budget Office (CBO) (2005) Uncertainty in analyzing climate change: policy implications. CBO Paper. Congressional Budget Office, Washington, DC.

Congressional Budget Office (CBO) (2008) Policy options for reducing $\mathrm{CO}_{2}$ emissions. CBO Study. Washington, DC: Congressional Budget Office, Washington, DC.

Crichton, M. (2004) State of Fear. Avon Books, New York.

Department of Trade and Industry (DTI) (2006) DTI Strategy for Sustainable Construction Consultation Events. Department of Trade and Industry, London.

Goulder, L.H. \& Pizer, W.A. (2006) The economics of climate change. Discussion paper RFF 06-06. Resources for the Future, Washington, DC.

Holmes, R. (2008) The Age of Wonder. Pantheon Books, New York.

Horner, C.C. (2007) The Politically Incorrect Guide to Global Warming and Environmentalism, Regnery Publishing, Washington, DC.

Intergovernmental Panel on Climate Change (IPCC) (eds.) (2007a) Climate Change 2007: Synthesis Report: Contribution of Working Groups I, II and III to the 
Fourth Assessment Report of the Intergovernmental Panel on Climate Change. Geneva, IPCC.

Intergovernmental Panel on Climate Change (IPCC) (2007b) Frequently asked questions: what is climate? Available from http://www.wmo.int/pages/prog/wcp/ $\mathrm{ccl} /$ faqs.html.

Intergovernmental Panel on Climate Change, Task Group on Data and Scenario Support for Impact and Climate Assessment (IPCC-TGICA) (2007) General Guidelines on the Use of Scenario Data for Climate Impact and Adaptation Assessment. Intergovernmental Panel on Climate Change, Task Group on Data and Scenario Support for Impact and Climate Assessment, Geneva.

Lawson, N. (2006) The economics and politics of climate change: an appeal to reason. Lecture to the Centre for Policy Studies. Centre for Policy Studies, London.

Lindsey, R. (2009) Climate and Earth's Energy Budget. NASA Earth Observatory, Greenbelt, MD.

Michaels, P.J. (2004) Meltdown: The Predictable Distortion of Global Warming by Scientists, Politicians and the Media. Cato Institute, Washington, DC.

Nodvin, S.C. (ed.) (2010) Global Warming. Environmental Information Coalition, National Council for Science and the Environment, Washington, DC.

Oregon Wild (2007) The straight facts on forest, carbon and global warming. Special Oregon Wild Report. Oregon Wild, Portland, OR.

Pielke, R.A. (2005) Heat storage within the Earth system. Forum: American Meteorological Society, 331-335.

Pielke, R.A., Davey, C. \& Morgan, J.A. (2004) Assessing global warming with surface heat content. EOS: American Geophysical Union, 85, 210-211.

Riebeek, H. (2010) Global warming. NASA Earth Observatory, Greenbelt, MD. Available from http://earthobservatory.nasa.gov/Features/GlobalWarming/.

Sedjo, R. (1993) The carbon cycle and global forest ecosystem. Water, Air, and Soil Pollution, 70, 295-307.

Stern, N., Peters, S., Bakhshi, V., Bowen, A., Cameron, C., Catovsky, S., Crane, D., Cruickshank, S., Dietz, S., Edmonson, N., Garbett, S.L., Hamid L., Hoffman, G. \& Ingram, T. (2006) Stern Review: The Economics of Climate Change. HM Treasury, London.

Tamirisa, N. (2007) Climate change and global economy. Finance and Development, 45 (1). Available from http://www.imf.org/external/pubs/ft/fandd/2008/03/ tamirisa.htm.

Trenberth, K.E. \& Fasullo, J.K. (2009) Earth's global energy budget. Bulletin of the American Meteorological Society, 90, 311-323.

Warwick, J.M. \& Wilcoxen, P.J. (2002) The role of economics in climate change policy. Journal of Economic Perspectives, 16, 107-129.

World Meteorological Organisation (2010) Understanding Climate. World Meteorological Organisation, London. 
